Typologies of suburban guardians: Understanding the importance of responsibility, opportunities, and routine activities in facilitating surveillance

\author{
Emily Moir ${ }^{1}$ \\ Griffith Criminology Institute \\ Griffith University \\ Mt Gravatt, QLD, Australia
}

Timothy C. Hart

Department of Criminology and Criminal Justice

University of Tampa

Tampa, FL, U.S.

Danielle M. Reynald

Griffith Criminology Institute

Griffith University

Mt Gravatt, QLD, Australia

and

Anna Stewart

Griffith Criminology Institute

Griffith University

Mt Gravatt, QLD, Australia

${ }^{1}$ Address all correspondence to: Emily Moir, School of Criminology and Criminal Justice, Griffith University, Mt Gravatt, QLD, Australia, 4122. Email: e.moir@griffith.edu.au. Phone: +61 (07) 37355627 



\begin{abstract}
Research suggests that personal and situational characteristics influence how and when residents provide guardianship over where they live (Reynald, 2010). However, there is limited empirical scholarship regarding what motivates residents to act as guardians and control crime in different contexts. The current study explores the role motivation and opportunity play in facilitating monitoring and intervention among potential guardians against crime in suburban Australia. Twenty semi-structured interviews with Brisbane suburban residents were conducted and suggested the existence of four typologies of suburban guardians: active, opportunistic, responsive, and non-guardians. Factors crucial to facilitating monitoring include the physical design of houses, relationships with neighbours, prior victimisation, and daily routine activities. Direct intervention is supported by feelings of responsibility and capability. Other themes found to support guardianship decision-making were also identified, and results suggest that residents supervise and monitor their street regardless of current crime rates. Implications for theory and practice, and directions for future research, are discussed.
\end{abstract}

Keywords: routine activity theory, monitoring, surveillance, active guardianship, suburbs, intervention 


\section{Typologies of suburban guardians: Understanding the role of responsibility, opportunities, and routine activities in facilitating surveillance}

According to Felson and Eckert (2016), to be effective at preventing crime, potential guardians must be in close proximity to places they are capable of supervising, have direct lines of sight to those locations, and have defined responsibilities to oversee them. Existing scholarship has linked the capacity to provide effective guardianship to three unique stages of "active" guardianship behaviour: availability, monitoring, and direct or indirect intervention (Reynald 2009). In general, existing active guardianship research shows that property crime decreases as active guardianship behaviour (e.g., monitoring and intervention) increases (Hollis-Peel et al. 2012; Reynald 2009).

The focus of existing active guardianship scholarship (Reynald 2009; Hollis-Peel and Welsh 2014; Reynald 2011a) is mostly on observing guardianship behaviours (i.e., do residents monitor and intervene when they see someone familiar on their street?). Moir et al. (2017) used observations to investigate how many residents were home in the Brisbane suburbs, and what proportion of those residents monitored and intervened when an unfamiliar observer was on their street. While this research showed that approximately three-quarters of visibly available residents monitored, and roughly half of those residents questioned the observer's presence in their residential area, the study did not investigate why residents' responded in such ways. The current study builds upon Moir et al's (2017) work to understand the individual motivations and environmental factors that facilitate or inhibit guardianship behaviours in Australian suburban residents. In doing so, our theoretical understanding of the role that guardians play in preventing crime will be expanded and context-specific crime control efforts may be improved.

Knowledge about opportunities for, and motivations behind, guardianship has been growing steadily in recent years, though it remains limited and additional research is warranted. Current interview studies suggest that perceptions of responsibility and capability, 
perceptions of crime in the area, and relationships with neighbours facilitate residential monitoring (Reynald 2010). Furthermore, when potential guardians see something suspicious, research has identified factors believed to influence their decisions to intervene, including a sense of responsibility, perceptions of area, prior security/police training, physical competence, safety, and availability of protective tools. Reynald (2010) is one of the only known interview studies so far to explicitly identify factors that influence monitoring and intervention by available guardians in residential areas. To our knowledge, no such study has been conducted in an Australian suburban context. In an attempt to fill this gap and build on research in this vein, the current study was undertaken to explore the role that motivation and opportunity play in facilitating monitoring and intervention among potential suburban guardians. In doing so, we sought to answer three research questions: (a) What factors facilitate monitoring by suburban guardians; (b) What factors influence intervention by suburban guardians; and (c) What types of guardians exist in suburban areas? Before answers to these questions are presented and typologies of suburban guardians identified, a review of the relevant literature is discussed in the following section.

\section{Guardianship In Action}

The Guardianship in Action (GIA) model describes three stages of guardianship intensity: availability, monitoring, and direct or indirect intervention (Reynald 2009). Guardianship intensity increases as a potential guardian's behaviour moves from simply being available to intervening to prevent an incident. Each of the three stages of guardianship intensity is discussed below in greater detail.

\section{Availability}

In residential areas, residents' capacity to serve as guardians against crime is affected by their everyday routine activities, such as work, social events, and activities at home, which influence when, and for how long, a resident is available to guard against crime (Felson and 
Eckert 2016). Extant studies support this point, finding that time of day influences guardianship availability, as commuters leaving residential areas at the start of the workday lowers the number of capable guardians available to prevent or disrupt crime (Reynald 2011b; Moir et al. 2017; Wickes et al. 2016). In the Brisbane suburbs, observed guardianship availability differed significantly based on the day of the week (Moir et al. 2017). Similar links between routine activities on weekends versus weekdays, guardianship availability, and residential burglaries have also been established (Ratcliffe 2001). Existing research also suggests that as guardianship availability increases, property crime rates decrease (Massey et al. 1989; Robinson 1999; Wickes et al. 2016).

Further, routine activities are reliant upon a number of spatial factors, including land use, road networks, and transport availability (Brantingham and Brantingham 1995), which differ across place (Stahura and Sloan 1988). Therefore, the availability of guardians will vary according to the context in which they live. For example, Australian cities have a far smaller population density than those in Europe or North America, affecting the number of available guardians (Spencer et al. 2015). The current research expands upon Moir et al. (2017) to provide a deeper understanding of how routine activities both within and outside the home affect guardianship behaviours.

\section{Monitoring}

Residents need to monitor their surroundings to enhance guardianship and security in residential areas (Felson and Eckert 2016). Several factors can influence monitoring habits by residents, including housing design, time, and personal characteristics (e.g., personality). For example, research shows that housing design can facilitate supervision by providing unobstructed views to the street or clear lines of sight between properties (Armitage 2013; Hollis-Peel et al. 2012; Reynald 2011a; Reynald 2009). In addition, the location of "active rooms" (rooms in which residents spend a majority of time awake) within a property can also 
affect residents' ability to monitor. The locations of these rooms within a home and the views they offer onto the street outside may strongly influence when and how long people can engage in monitoring behaviour (Armitage 2013; Brantingham et al. 2017). Housing design that maximises visibility of a residents surroundings allows them to directly observe- either deliberately or passively — what is happening in their proximate environment, thereby increasing their ability to act as an effective guardian to disrupt and prevent crime opportunities (Reynald 2011b; Ekblom 2011).

Monitoring is also influenced by the time of day. Reynald and Elffers (2015) found that Dutch residents' monitoring intensity fluctuated throughout the day. The highest levels of monitoring took place in the mornings, whereas the lowest occurred in the evenings and late at night. Similarly, Reynald (2011b) also found meaningful differences between observable daytime and night-time guardianship intensity: monitoring decreased significantly at night compared to during the day, demonstrating that the efficacy and intensity of guardianship changes over the course of the day.

Residents' personal characteristics and attitudes have been linked to supervision patterns. In a sample of Dutch residents, attitudes towards acting as a guardian and valuing courage, perceptions of responsibility and crime, and security training positively predicted supervision intensity (Reynald and Moir Forthcoming). Perceptions of a person's residential area and relationships within that area can also influence willingness to monitor (Reynald 2010; Greenberg and Rohe 1984; Foster 1995; Weisburd 2012). Therefore, when residents perceive themselves as capable guardians and have positive perceptions of their area, supervision levels are enhanced.

Collectively, existing scholarship indicates that the unique physical and social context of where someone lives can impact on their willingness to monitor their surroundings (Groff 2015; Weisburd 2012; Reynald 2011a; Reynald 2010), but so far, studies in this field have 
predominately used Dutch samples, (Reynald and Moir Forthcoming; Reynald and Elffers 2015; Reynald 2010). As these factors differ across space (Dines and Vermeulen 2013), an exploration into how and why suburban residents monitor their surroundings would contribute our existing knowledge of guardianship behaviour.

\section{Intervention}

Demographic characteristics and situational factors have been shown to affect an individual's decision to intervene in a crime event. For example, six situational and personal characteristics were found to affect guardian's decisions to intervene when they witnessed a crime or something suspicious (Reynald 2010). These included their perceptions of responsibility and their surroundings, threats to safety, and prior emergency training. Furthermore, Hart and Miethe (2008) demonstrated which situational contexts of non-fatal violent crime, (defined by the crime type, location of an incident, use of weapon, and victimoffender relationship) influenced a bystander's decision to intervene and was perceived as most beneficial to the crime victim. For example, intervention was often effective in sexual assault situations without a dangerous weapon and stranger robberies in public places. It is hypothesized that in such situations where there is low ambiguity that there is an ongoing offence occurring and low risk of physical harm due to lack of weapons, helpful intervention is increased. The seriousness of the incident influences people's reactions, with some research suggesting that people are more likely to intervene in high-harm situations (Fischer et al. 2011), while others would be reticent to directly intervene if they thought their personal safety was in danger (Reynald 2010), or believed police were effective or responsible for crime control (Schaefer et al. 2017). Further, understanding how to intervene, and skills required to intervene are critical in whether someone will get directly involved in a variety of crimes, including violent crime (Huston et al. 1981). Collectively, current research suggests 
that before an individual intervenes in a troublesome event, they consider the situation and whether they are likely to be hurt by doing so.

Social ties and relationships have also been shown to be important in intervening behaviour. Warner's (2007) work demonstrated that residents' willingness to directly intervene was significantly higher in areas with stronger social ties. In an Australian context, using survey measures of Brisbane residents, respondents with higher levels of contact with their neighbours were more likely to take action (either directly or indirectly) in local drug problems, vandalism, and young people getting into trouble (Schaefer et al. 2017). Overall, while research shows what residents do in response to witnessing crime, there is limited study into why residents act. The current research addresses this research gap by interviewing residents about witnessing crime, how they responded, and the motivations behind their response.

\section{Current Study}

Overall, both characteristics of individuals (e.g.., perceptions of capability) and situations (e.g., seriousness of the event) influence how and when someone can monitor and intervene in crime events. Further, place-based characteristics are critical in facilitating opportunities for residents to be present, monitor their surroundings, and intervene if necessary (Reynald 2011a; Wilcox et al. 2007). To date, our understanding of specific factors believed to facilitate monitoring and intervention among residential suburban guardians is limited (Moir et al. 2017; Schaefer et al. 2017). In response, the current study examines the role that motivation and opportunity play in facilitating monitoring and intervention among suburban residents; and in doing so, we answer three research questions:

1. What individual and situational factors facilitate monitoring by suburban guardians?

2. What factors influence intervention by suburban guardians?

3. What types of guardians exist in suburban areas? 
The following sections provide a description of the data and methodology used in the current study to answer these questions and to develop typologies of suburban guardians.

\section{Data and Methodology}

Data for the current study were collected through semi-structured interviews, conducted with 20 residents living in the Wavell Heights and Northgate-Virginia suburbs of Brisbane, Australia. As perceptions of a resident's area and relationships with neighbours can influence their willingness and ability to act as a guardian (Reynald 2010; Weisburd 2012), questions related to these topics were asked to elicit how the participant's social context might influence their behaviour. Participants were also asked to describe what views they have of the street and neighbouring properties from their residences to understand what surveillance opportunities were available to them (Reynald 2011a; Hollis-Peel et al. 2012). In keeping with Reynald (2010), participants were questioned about their monitoring habits, motivations for monitoring, whether they witnessed anything suspicious on their street, and how they responded in those situations. Responses were elicited to identify factors that influence a potential guardian's decision to monitor, to intervene and form of intervention (i.e., direct or indirect). Interviews were recorded and transcribed for the analysis that follows.

\section{Sample}

Households where potential interviewees lived were purposively selected for the current study using Conjunctive Analysis of Case Configuration ${ }^{1}$ (CACC; Miethe et al. 2008). Using CACC to identify households enabled the research team to match two Brisbane suburbs that were socio-demographically similar, but with different property crime rates. As socio-demographic characteristics have been shown to affect the willingness and extent of potential guardians in residential areas (Reynald 2011a; Reynald 2010), these characteristics were controlled for in the suburb sampling process. 
Both suburbs selected in the sampling procedure (i.e., Wavell Heights and NorthgateVirginia) are located approximately 13-16 kilometres north of the Brisbane Central Business District. Relative to other Brisbane suburbs, Wavell Heights and Northgate-Virginia are both average in population growth, disadvantage, ethnic presence, proportion of family households, residential mobility, and low in the proportion of male youth (i.e., potential offenders $)^{2}$. Wavell Heights had a lower-than-average property crime rate, while NorthgateVirginia had a higher-than-average property crime rate at the time interviews were conducted. From both suburbs, 12 street segments were randomly selected, resulting in a sample of 278 properties with 379 unique addresses.

To identify interviewees living within sampled suburbs that were willing to participate in the current study, two researchers went from property to property, along sampled street segments, doorknocking from June to August 2015. Doorknocking took place on weekdays from 9:00am - 4:00pm. If no one was home, a letterbox drop with details of the study was completed. Approximately a quarter of properties were not contactable as either no one was home, there was a "No Doorknocking" sign on their property, or there were "No Junk Mail”/“Australia Post Only” stickers on their letterbox.

Doorknocking resulted in 20 residents agreeing to be interviewed, including 11 from the low crime suburb (i.e., Wavell Heights) and nine from the high crime suburb (i.e., Northgate-Virginia). Interviews took on average 30 minutes to complete. The average age of the interviewees was $47(S D=14.5)$ and had lived at their current address for an average of nine years $(S D=7.9)$. Presented in Table 1 are other socio-demographic characteristics of the sample, which show the majority were female, had completed an undergraduate degree, were married and lived with their family, Australian born, and employed full-time at the time of this study. The sample used in the current study is not representative of the Brisbane 
population more generally, with interviewees comprising more Australian born, university educated, and married individuals (Australian Bureau of Statistics 2011).

\section{INSERT TABLE 1 ABOUT HERE}

\section{Analytic Approach}

An informant-by-variable matrix was used to analyse data obtained from the 20 interviewees (Miles et al. 2014). This approach focuses on three stages of qualitative data analysis: data reduction, data display, and conclusion drawing/verification. In accordance with this strategy, interview data obtained for the current study were reduced through coding by reading each transcript line-by-line and attaching labels of codes. Codes were determined from research questions, theoretical frameworks, and preliminary analysis of the transcripts. Eight codes were used to reduce data: (a) perceptions of area, (b) relationship with neighbours, (c) surveillance opportunities, (d) contextual awareness, (e) routine activities, (f) witnessing of incidents, (g) monitoring behaviours, and (h) intervention.

Next, data were displayed in the matrix. Rows represented the 20 interviewees and columns represented the codes described previously. Miles et al.'s (2014) 10 rules of thumb were followed to ensure data was entered into the matrix appropriately, and text in each cell consisted of short blocks of texts, direct quotes, and researcher explanations.

Finally, conclusions were drawn and verified using Miles et al.'s (2014) 11 guidelines. Multiple methods were used in this stage including noting patterns and themes, exploring similarities and differences between participants, including specific examples, re-checking preliminary conclusions, and checking for contradictory evidence.

\section{Results}

The current study answers three questions related to the role that motivation and opportunity play in facilitating monitoring and intervention among potential guardians living 
in suburban Brisbane households. The first of these question asks, "What individual and situational factors facilitate monitoring by suburban guardians?"

\section{Factors Affecting Monitoring}

Results from analyses of data obtained from our sample of 20 interviewees enabled us to identify four themes that affect monitoring by suburban residents: (a) physical design of the house, (b) relationships with neighbours, (c) prior victimisation, and (d) residents' routine activities.

\section{Physical design of the house}

Consistent with past research, data collected from interviewees suggest that housing design facilitated their monitoring habits (Reynald 2011a; Reynald 2009; Armitage 2013). In order for a resident to monitor, the opportunity to do so must be present. Collectively, three types of potential guardians were identified in the interview data, based on the influence of their reported visibility and monitoring patterns:

1. Those with clear views and opportunity to monitor;

2. Those with clear views, but who did not monitor;

3. Those with obstructed views that prevented supervision of their surroundings;

Overall, $65 \%$ of residents indicated that they had clear views to the street from some point in their property, which allowed them to see their street and neighbouring properties:

P2: "It's elevated, with glass sliding doors, so probably a good vision of the area... we have a very close sensation of what's going on."

Interestingly, $10 \%$ of interviewees explained that although they had clear views to the street from inside their house, they generally chose not to monitor. One participant explained, “There's just no motivation to. I don't see the point being nosy around the street" (P13). This statement reflects that monitoring is not an automatic process and willingness and motivations play important roles in facilitating guardianship among suburban residents. 
Finally, there was a small subgroup (25\%) of interviewees identified who could not monitor their surroundings because the design of their property inhibited such behaviour:

P16: "Well, I don't see a great deal because I'm kinda in the corner... so I don't see what's happening out on the street."

\section{Relationships with neighbours}

Relationships with neighbours emerged as a second theme that influenced how and when interviewees supervised their surroundings. Approximately two-thirds of participants had positive relationships with their neighbours. Good relationships with neighbours enhanced guardianship in that (a) residents looked after each other's properties, and (b) residents knew who lived on their street, meaning they could recognise familiar and unfamiliar people, including potentially suspicious individuals. One participant monitored their surroundings to ensure that "nothing happens to myself or the neighbours" (P17). Another participant explained:

P18: "They're all quite friendly and we, we keep an eye on their houses."

A small proportion of suburban residents (15\%) did not monitor as they reportedly did not know their neighbours. This occurred on streets with several apartment blocks, with high residential mobility, which appeared to increase the difficulty for residents to build relationships with neighbours and recognise each other. A lack of monitoring meant these residents had limited knowledge of who belonged on their street, which decreased their ability to detect someone or something suspicious. This was best described by one participant who stated:

P14: "This street seems to be much more itinerant sort of street where people come and go...I wouldn't have a clue who lives next door to us now." 


\section{Prior victimisation}

Of the 20 participants interviewed for the current study, $45 \%$ reported a prior burglary victimisation $^{3}$. Among this group of suburban residents, having been victimised appeared to serve as an important catalyst for deliberate and active monitoring of their surroundings to (a) look out for potential offenders and (b) to prevent repeat-victimisation.

As one participant who had been burgled the prior year explained:

P7: "Yeah [I monitor] every time I go out. If I see a couple of people you know, with hoodies on that look, not very friendly type people, I always have a look, see who it is. I like to check out who they are, after being broken into.... So I'm always conscious of who's walking up and down the street. If I see someone I take note of who it is for that reason."

However, for a sub-set (22\%) of other residents who were victimised, they put their efforts into target hardening their homes to prevent re-victimization rather than extending their vigilance through monitoring.

\section{Residents' routine activities}

Finally, suburban residents' routine activities at home (e.g., cooking, reading on their balcony, playing with children in the front yard) influenced when and for how long they reportedly surveyed their surroundings. Depending on where these activities took place, opportunities for surveillance could be facilitated or hindered. For instance, two interviewees explained that they have clear, unobstructed views from their kitchen windows, where they spent a lot of time. This allowed them to engage in passive surveillance over their street.

P19: "Because I spend a bit of time in the kitchen cooking, in my day when I'm not at work, I'm at home... so I'll just naturally be looking out."

Likewise, other suburban residents reportedly spent considerable time on their balconies, allowing them to passively monitor their street and build their contextual awareness of who and what was "normal" activity in their surrounding areas. As they 
explained, time spent outside made them "more aware of what's going on out the front" (P4). Although monitoring was not the primary purpose of these activities, the location of where they take place allowed residents to monitor and build an understanding of regular activities in their area.

\section{Factors Affecting Intervention}

During interviews with suburban residents, participants were asked if they had ever witnessed a crime or something suspicious on their street. If so, they were then asked how they responded. Seventy-five percent of interviewees reportedly witnessed at least one incident ${ }^{4}$. Collectively, these residents reportedly witnessed a total 22 suspicious or crime events on their streets. The most common responses to an incident that was reportedly witnessed was continued monitoring of the situation. Four categories of responses to incidents were derived from themes identified in the interviewee data: (a) direct intervention, (b) indirect intervention, (c) continued monitoring, or (d) doing nothing. Percentages of actions taken associated with each of these responses are presented in Table 2. Data on the type of actions undertaken when interviewees reportedly intervened were used to answer our second research question: "What factors influence intervention by suburban guardians?"

\section{INSERT TABLE 2 HERE}

\section{Direct intervention}

In about $23 \%$ of cases when something suspicious was witnessed on their street, suburban residents reportedly intervened in the situation directly. Three factors appeared to influence decisions to directly intervene, including, to prevent harm, the seriousness of the event, and experience with training. One participant explained their actions after witnessing an assault outside of his property:

P2: "I needed to intervene in case someone was injured...As part of my job, it's very varied cause there's a security aspect there as well where we deal with lucid and aggressive persons." 


\section{Indirect intervention or monitoring}

More common responses to suspicious or crime events were to intervene indirectly or to continue monitoring the scene. Combined, these responses accounted for about $68 \%$ of all responses to incidents that were reportedly observed. In these situations, suburban residents were reluctant to intervene directly for three common reasons:

1. Issues of personal safety and ambiguity of events;

2. Attitudes of police role in crime prevention and event de-escalation; and

3. Inexperience of how to diffuse situations.

Issues of personal safety were the most common response for why residents were reluctant to intervene directly, with $80 \%$ considering their safety in their decision-making process. The uncertainty of the event and what could happen to them, or if the situation could escalate, was particularly common among female participants.

P12: "I guess its fear of being injured or hurt yourself, I guess, you know, the unpredictability of someone who would be doing that."

Other participants who were reluctant to intervene directly did not see themselves as active crime fighters and saw police as the official and professional agency that was suited to deal with crime. They did not think they had the skills and ability to respond to crime events or suspicious people, unlike police. As participants explained:

P6: "You'd just call the police because it's just not safe to go out and actually intervene."

Coupled with this was the belief that participants did not have the appropriate skills to know how to intervene directly or de-escalate situations. Another female participants added:

P16: "I don't think that I am equipped to deal with people like that."

\section{Doing nothing}

Two interviewees explained that they did nothing regarding a potential crime event or public nuisance offence that they reportedly observed. Interestingly, the seriousness of the 
observed event determined their responses in opposite ways. One participant witnessed juveniles jump a fence onto the train tracks opposite her street; however, she did not think this required anything further:

P19: "I just thought 'Oh yeah, you look a bit dodgy' and that's about it."

For another participant, his previous neighbours would have loud verbal arguments; however, he stated that he, "Stayed away from them. They were too violent...I didn't want to get involved" (P5).

Overall, interviews with suburban residents indicate that responses to witnessing a crime or suspicious event are diverse and the context of the situation is important for residents in deciding whether they will intervene.

\section{Typologies of Guardians}

From interviews conducted with suburban Brisbane residents, there is empirical evidence that motivations and opportunities to monitor their surroundings differ. As such, the final research question of the current paper answers the question, "What types of guardians exist in suburban areas?" A total of four guardianship typologies were identified in the interview data: (a) purposefully active monitors (PAMs), (b) passive opportunistic monitors (POMs), (c) responsive monitors (REMs), and (d) non-monitors (NOMs). These classifications are not static as $70 \%$ of interviewees were associated with more than one typology. In other words, findings suggest that conditions and opportunities for guardianship are dynamic.

\section{Purposefully active monitors (PAMs)}

Purposefully active monitors are suburban residents whose monitoring of their surroundings for potential problems is deliberate. Four interviewees $(20 \%)$ who participated in the current study were identified as PAMs. They resided in both low-crime (50\%) and high-crime $(50 \%)$ areas. Prior victimisation and crime prevention were powerful determinates 
in participants being classified as PAMs. As one resident explained, they monitored their street due to a burglary the prior year:

P7: "I monitor every night. I check the front out here before I go to bed and most of the time I see...the people that look like they would be potential people to break in to a house."

Existing relationships with a neighbour also facilitated monitoring. One resident explained that they monitored their surroundings, "to keep an eye on things. Just to make sure nothing happens to myself or the neighbours" (P17).

For other residents, they monitored for enjoyment, but also to see who was near their house. When one residents was asked if they ever monitor their street, they responded:

P19: "Oh all the time probably. Just, It's something to do as well...it's just a stickybeak ${ }^{5}$ sort of thing. I'd probably do it, you know, every five minutes or so...you tend, you know, look for interest sometimes. So if someone was walking, or a dog walking past, have a look...if someone stops at night time and the blinds are down, we tend to sort of get up and have a poke, just see if they're coming here."

This small group of residents have both motivation and opportunities to engage in monitoring, and monitored to keep their area secure and to see who on their street. However, this group had the fewest members (20\%). As Poyner and Webb (1991) explain, "motivation is not enough" (p. 30) for offenders and that opportunity also plays a role in explaining crime. The same argument appears to be applicable to guardianship, based on current observations. Opportunities must also exist for suburban residents to act as capable guardians.

\section{Passive opportunistic monitors (POMs)}

Consistent with past research (Reynald, 2010), data from our interviews suggest that monitoring was not an automatic process. Thirteen residents $(65 \%)$ were classified as passive opportunistic monitors (POMs) who passively engaged in monitoring without a predetermined motive. This suggests that crime and suspicious activity are not the only driving force behind monitoring behaviour. Two factors emerged that together influenced 
POMs: (a) housing design allowed natural surveillance over the street, and (b) routine activities which provided opportunities to monitor.

First, some houses naturally facilitated supervision of the street by offering clear, unobstructed views. As residents explained:

P19: "Yeah, well the kitchen...you can see out of those side windows onto the street, so yes...someone walks past, you kinda just check out who it is, or a car stops, you sort of check it out. It's a pretty good view out that side."

Second, opportunities for monitoring manifested from residents' daily routines. At the micro level, residents had particular daily routines while at home. For those residents, daily routines such as cooking, playing with the children in their front yard, or having an afternoon drink on their front verandah facilitated opportunities for them to passively monitor. For instance:

P4: "So I'll often sit out there [front verandah] and read, so that kind of, you know, you're more aware of what's going on out the front."

The intersection between daily routine activities, where they occurred on residents' property, and what views to the street were offered from these spaces were important in providing opportunities to passively monitor the street. Regardless of the intention, this type of monitoring still meant that suburban residents built a contextual awareness of the routines and people in their surroundings.

\section{Responsive monitors (REMs)}

Those who monitored in response to a stimulus were the most common type of guardian identified in the current study. Sixteen of the 20 interviewees (80\%) reportedly monitored their surroundings in response to a noise or event that captured their attention. Although most of the guardianship literature focuses on how visual stimuli facilitate guardianship action (e.g., Reynald, 2010), this study demonstrates how auditory stimuli was the predominant catalyst for responsive monitors. However, contextual awareness was critical 
in determining whether this type of stimulus was suspicious or unusual. After living in an area, these responsive monitors (REMs) were able to build an awareness of what normally occurs, and when. For many interviewees identified as REMs, it was only after they heard something outside of this normal pattern on their street that they would go out and see what was happening:

P15: "Normally if I hear something, so if I hear screeching tires or something out of the ordinary, like it's so peaceful now, if people are talking loudly if they walk along the street, I often look out and see what's going on."

To these suburban residents, a sound that suggested something out of the ordinary sparked their attention and they responded by monitoring what was going on.

\section{Non-monitors (NOMs)}

Five residents (25\%) explained that they generally did not monitor and these interviewees were classified as non-monitors (NOMs). Three of these residents lived in the low crime suburb. Three reasons could explain this lack of supervision: (a) lack of ability, (b) pre-occupied with other activities, or (c) no motivation.

First, for some suburban residents, there was a lack of structural ability to monitor their surroundings as views were impeded:

P3: "I don't look out that side, the view is too obscured that way."

Second, these residents also spoke about not engaging in supervision, as they were preoccupied with other activities inside their home, such as child rearing and household chores. When asked if they monitored, residents responded:

P4: "I'm too busy doing other things...If I hear a car that kind of feels like there's loitering out the front, or might be driving into our drive, you know, I will respond to that, but otherwise, you know."

Third, some suburban residents did not feel the need to supervise, or there was no motivation to do so. Lack of motivation stemmed from feelings of safety or that it was not a necessary task required of them. 
P13: "There's just no motivation to. Unless there's a reason for it then I don't see the point being nosy around the street...I don't really need to actually look out."

\section{Discussion}

Data collected from interviews conducted with 20 residents living in high-crime and low-crime suburbs of Brisbane, Australia, enabled us to explore the role that motivation and opportunity play in facilitating monitoring and intervention among potential guardians. We did so by identifying the factors that facilitate monitoring by suburban guardians; the factors influence intervention by suburban guardians; and the types of guardians exist in suburban areas.

Table 3 presents a summary of these findings, where four general observations can be gleaned.

\section{INSERT TABLE 3 ABOUT HERE}

First, resident responses show that both individual and situational factors affect how and when suburban residents act as capable guardians. The current study supports research that shows how physical environments can maximise opportunities for surveillance for residents to observe what is happening around them (Armitage 2013; Reynald 2011a; Poyner and Webb 1991). However, supervision habits were not solely explained by the built environment — numerous individual factors also affected decisions and opportunities to monitor, including residents' daily routines. These findings lend support to prior work illuminating the role of quality relationships with neighbours and perceptions of responsibility on enabling crime control behaviour (Reynald 2010; Foster 1995). In responding to incidents, factors which determined whether to intervene and what action to take largely supported Reynald's (2010) work, finding threats to safety and seriousness of events played roles in guardian's decision making process. 
Second, results from the current study show routine activities affect opportunities for guardianship. Prior research has predominately focused on how routine activities enable opportunities for offending and/or victimisation (e.g., Mustaine and Tewksbury 2000), or how daily routines affect household availability — the prerequisite to capable guardianship (e.g.Felson 1995; Moir et al. 2017). However, this study shows that what suburban residents do at home (i.e., micro routine activities) affect when, and for how long, residents monitor, supporting the conjecture that where people spend time in their homes can affect supervision (Armitage 2013; Brantingham et al. 2017). As Reynald and Elffers (2015) assert, availability does not equate to supervision, so it is important to understand where and what a person does when they are at home and how this can affect guardianship opportunities. These microroutine activities determined monitoring habits, which increased contextual familiarity, which in turn, further helped effective guardianship over residents' micro-places.

Third, the development of guardian typologies reinforces that suburban residential crime control behaviour can be both proactive and reactive (e.g. Reynald 2011b). For active monitors, guardianship worked as a proactive behaviour, and was often used to prevent crime and re-victimisation. This is similar to findings from Greenberg and Rohe's (1984) study, in which residents who lived in high-crime areas were more likely to monitor for unfamiliar people or suspicious activities. In addition, for some suburban residents, monitoring their street was part of their "security routine" for crime prevention (Ekblom 2011). Individual factors such as responsibility and motivation to provide guardianship were clear catalysts for this group of residents (Felson and Eckert 2016). On the other hand, the majority of residents passively monitored without a determined motive or guardianship worked as a reactive behaviour to stimulus. Results suggests guardians are heterogeneous, and display different behaviours based on their circumstances — both personal and situational, similar to offenders (Wortley 2012). No resident was completely disengaged from monitoring their surroundings; 
and likewise, even active monitors did not monitor all the time. Interestingly, there were no dramatic differences in the guardianship patterns exhibited by residents across the low and high crime suburbs. As such, guardianship may function irrespective of crime (or perceptions thereof).

Fourth, suburban residents' contextual awareness helped the efficacy of guardianship in their areas. Monitoring, whether passive or deliberate, helped residents build an understanding of what, and who, was normal (or abnormal) on their street, making them more effective guardians. Further, high levels of contextual awareness assisted residents' decision about whether some type of intervention was necessary when events were reportedly witnessed. These results confirm Felson's (2006) and Reynald's (2009; 2011a) ideas about how contextual familiarity increases capable guardianship. Overall, this study found guardianship by suburban residents is shaped by daily routines and opportunities, relationships, responses to stimulus, protection against victimisation, and personal motivations.

\section{Limitations and Future Directions}

Although the current study provides important insights into factors that facilitate guardianship in suburban areas, the project has certain limitations that must be acknowledged. First, the sample used in the current study was small and comprised of a fairly homogenous group - Caucasian, middle-aged, highly-educated Australians, who did not live in disadvantaged areas. Further, residents who agreed to be interviewed and were available at home during the day were drawn from only two suburbs. While results from the current study seem to be consistent with prior research (e.g. Reynald 2010), replication is required to understand the generalizability of the guardian typologies in different contexts.

Another avenue for future research would be to extend guardianship research beyond private, residential spaces. Multiple authors have suggested the need to examine guardianship 
in other contexts, including public space (e.g.Hollis-Peel et al. 2012). Offenders do not offend in each context (Wortley 2012), and guardians may not act as capable guardians in each context either. While residents may feel a responsibility to guard their private residential space (Felson \& Eckert, 2016), this level of responsibility may be diminished in public areas. This type of research could provide important insights into how different environments provide different opportunities and responsibilities for guarding.

\section{Policy Implications}

Regardless of the limitations, the current study suggests important implications for policy, both in terms of housing design and residential crime prevention. Felson and Eckert (2016) explain that we cannot rely on citizens to act as guardians if they cannot see other's homes and do not have a defined responsibility. Therefore, promoting guardianship in residential places requires (a) good housing design, and (b) residents who feel personally responsible for controlling crime in their surroundings. First, results highlight the importance of surveillance opportunities in fostering monitoring by residents. By implementing housing design that facilitates supervision, secure residential environments can be built to naturally prevent crime (Armitage 2013). Second, individual factors also emerged as important motivators of guardianship habits. Strategies that aim to bolster guardianship should focus on defining responsibility for residents to guard over their immediate areas. Ekblom's (2011) CLAIMED approach outlines strategies to empower and mobilise citizens to act as crime preventers, and could be applied to residential areas. CLAIMED summarises the tasks crime prevention practitioners need to undertake to facilitate people becoming active crime fighters. It seeks to clarify what action needs to be taken against a crime problem, locate key individuals who are best placed to undertake this action, alert those people to their ability to prevent crimes, inform them of the crime problem and the role they can play in prevention, motivate change, empower them to undertake crime control strategies and behaviour, and direct them on how 
to do so. Examples of strategies that could be aimed at facilitating residential surveillance include informing residents of a particular area their ability to stop/disrupt crime, motivating residents to engage in more active surveillance, and supplying them with the skills and knowledge of how to do so.

\section{Conclusion}

To summarise, this study demonstrates that suburban guardians are heterogeneous, and this behaviour is facilitated by both individual and environmental factors. Strategies to increase capable guardianship over suburban areas need to target both of these factors to create safe communities.

\section{Endnotes}

\footnotetext{
${ }^{1}$ Using nominal or ordinal level measures, CACC considers all possible combinations of variable categories simultaneously (Miethe et al. 2008). The number of possible case configurations depends on the number of variables used in the analysis and the number of categories associated with each. For the current study, continuous measures were recoded into new categorical measures using quartiles (i.e., the lowest and highest $25 \%$ and the average 50\%). Seven variables, each with three categories, were used in sample selection to create socio-demographic profiles of Brisbane suburbs. Although 2,187 combinations of unique socio-demographic profiles were possible $\left(3^{7}=2,187\right)$, only 99 were observed in Brisbane. Two suburbs were matched on all characteristics except levels of property crime (i.e., Wavell Heights and Northgate-Virginia).

${ }^{2}$ Moir et al. (2017) provides a detailed description of the sampling process for the suburb and street segments. Stratified random sampling was used to select an equal mix of high property crime street segments and no property crime street segments from each suburb $(n=822)$. Street segments which were non-residential are had more than 16 properties were excluded $(n=394)$. Street segments were classified based on the amount of crime they experienced-either high crime or no crime. "High crime" street segments were operationalised as a street segment on which a minimum of three property offences were reported across the three year period, one of which was an unlawful entry offence. From these, 12 were randomly selected from each suburb: (a) six no reported property crime street segments in the low crime suburb (b) six high property crime street segments in the low crime suburb, (c) six no reported property crime street segments in the high crime suburb, and (d) six high property crime street segments in the high crime suburb.

${ }^{3}$ Out of the nine reported burglaries, six $(67 \%)$ reported incidents occurred in the low-crime suburb.

${ }^{4}$ Out of the 15 witnessed events across both suburbs, (nine) $60 \%$ were witnessed by residents in the high-crime suburb. As such, all residents living in the high-crime suburb had witnessed a crime or something suspicious occurring on their street segment, compared to 55\% of residents in the low-crime suburb.

5 'Sticky beak' is Australian slang for being nosy and prying into other people's business.
} 


\section{References}

Armitage, R. 2013. Crime Prevention Through Housing Design: Policy and Practice. Hampshire, UK, Palgrave Macmillan.

Australian Bureau of Statistics. 2011. 2011 Census Community Profiles (website). Available online

http://www.censusdata.abs.gov.au/census_services/getproduct/census/2011/communit yprofile/3GBRI?opendocument\&navpos=230 Accessed 3 May 2013.

Brantingham, P.J., and Brantingham, P.L. 1995. Criminality of Place: Crime Generators and Crime attractors. European Journal on Criminal Policy and Research, 3(3), 1-26.

Brantingham, P.J., Brantingham, P.L, and Andresen, M. A. 2017. Geometry of Crime and Crime Pattern Theory. In: Wortley, R., and Townsley, M. (eds.) Environmental Criminology and Crime Analysis. 2nd ed. Oxon, UK: Routledge.

Dines, M., and Vermeulen, T. 2013. Introduction. In Dines, M., and Vermeulen, T. (eds.) New Suburban Stories. London: Bloomsbury Publishing.

Ekblom, P. 2011. Crime Prevention, Security and Community Safety Using the 51s Framework. Hampshire, UK: Palgrave McMillan.

Felson, M. 1995. Those Who Discourage Crime In: Eck, J. E., \& Weisburd, D. (eds.) Crime and Place: Crime prevention studies. Monsey, NY: Criminal Justice Press.

Felson, M., and Eckert, M. 2016. Crime and Everyday Life. Thousand Oaks, CA: Sage Publications.

Fischer, P., Krueger, J. I., Greitemeyer, T., Vogrincic, C., Kastenmuller, A., Frey, D., Heene, M., Wicher, M, and Kainbacher, M. 2011. The Bystander-Effect: A Meta-Analytic Review on Bystander Intervention in Dangerous and Non-Dangerous Emergencies. Psychological Bulletin, 137(4), 517-537.

Foster, J. 1995. Informal Social Control and Community Crime Prevention. The British Journal of Criminology, 35(4), 563-583.

Greenberg, S.W., and Rohe, W.M. 1984. Neighborhood Design and Crime: A Test of Two Perspectives. Journal of the American Planning Association, 50(1), 48-61.

Groff, E.R. 2015. Informal Social Control and Crime Events. Journal of Contemporary Criminal Justice, 31(1), 90-106.

Hart, T.C., and Miethe, T.D. 2008. Exploring Bystander Presence and Intervention in Nonfatal Violent Victimization: When Does Helping Really Help? Violence and Victims, 23(5), 637-651. 
Hollis-Peel, M.E., Reynald, D.M, and Welsh, B. 2012. Guardianship and Crime: An International Comparative Study of Guardianship in Action. Crime, Law and Social Change, 58(1), 1-14.

Hollis-Peel, M.E., and Welsh, B. 2014. What Makes a Guardian Capable? A Test of Guardianship in Action. Security Journal, 27(3), 320-337.

Huston, T.L., Ruggiero, M., Conner, R, and Geis, G. 1981. Bystander Intervention into Crime: A Study Based on Naturally-occurring Episodes. Social Psychology Quarterly, 44(1), 14-23.

Massey, J.L., Krohn, M.D, and Bonati, L.M. 1989. Property Crime and the Routine Activities of Individuals. Journal of Research in Crime and Delinquency, 26(4), 378-400.

Miethe, T.D., Hart, T.C, and Regoeczi, W.C. 2008. The Conjunctive Analysis of Case Configurations: An Exploratory Method for Discrete Multivariate Analyses of Crime Data. Journal of Quantitative Criminology, 24(2), 227-241.

Miles, M. B., Huberman, A. M, and Saldana, J. 2014. Qualitative Data Analysis: A Methods Sourcebook. Thousand Oaks, CA: Sage Publications.

Moir, E., Stewart, A., Reynald, D.M, and Hart, T.C. 2017. Guardianship in Action (GIA) Within Brisbane Suburbs: Examining the Relationship Between Guardianship Intensity and Crime, and Changes Across Time. Criminal Justice Review, Advanced online publication.

Mustaine, E. E., and Tewksbury, R. 2000. Comparing the Lifestyles of Victims, Offenders, and Victim-Offenders: A Routine Activity Theory Assessment of Similarities and Differences for Criminal Incident Participants. Sociological Focus, 33(3), 339-362.

Poyner, B., and Webb, B. 1991. Crime Free Housing. Oxford, UK: Butterworth-Architecture.

Ratcliffe, J. 2001. Policing Urban Burglary. Canberra: Australian Institute of Criminology.

Reynald, D. M. 2009. Guardianship in Action: Developing a New Tool for Measurement. Crime Prevention and Community Safety, 11(1), 1-20.

Reynald, D. M. 2010. Guardians on Guardianship: Factors Affecting the Willingness to Supervise, the Ability to Detect Potential Offenders, and the Willingness to Intervene. Journal of Research in Crime and Delinquency, 47(3), 358-390.

Reynald, D. M. 2011a. Factors Associated with the Guardianship of Places: Assessing the Relative Importance of the Spatio-physical and Sociodemographic Contexts in Generating Opportunities for Capable Guardianship. Journal of Research in Crime and Delinquency, 48(1), 110-142.

Reynald, D. M. 2011b. Guarding Against Crime: Measuring Guardianship within Routine Activity Theory. Surrey, UK: Ashgate Publishing. 
Reynald, D. M., and Elffers, H. 2015. The Routine Activity of Guardianship: Comparing SelfReports of Guardianship Intensity Patterns with Proxy Measures. Crime Prevention and Community Safety, 17(4), 211-232.

Reynald, D. M., and Moir, E. Forthcoming. Who is Watching: Exploring Individual Factors that Explain Supervision Patterns Among Residential Guardians.

Robinson, M. B. 1999. Lifestyles, Routine Activities, and Residential Burglary Victimization. Journal of Crime and Justice, 22(1), 27-56.

Schaefer, L., Mazerolle, L, and Kapnoulla, M. 2017. Different Actions for Different Crimes: Explaining Individual Action in Local Crime Problems. Journal of Community Psychology, 45(7), 922-939.

Spencer, A., Gill, J, and Schmahmann, L. 2015. Urban or Suburban? Examining the Density of Australian Cities in a Global Context. State of Australian Cities Conference 2015. Sydney.

Stahura, J. M., and Sloan, J. J. 1988. Urban Stratification of Places, Routine Activities and Suburban Crime Rates. Social Forces, 66(4), 1102-1118.

Warner, B. D. 2007. Directly Intervene or Call the Authorities? A Study of Forms of Neighborhood Social Control Within a Social Disorganization Framework. Criminology, 45(1), 99-129.

Weisburd, D. 2012. Bringing Social Context Back into the Equation. Criminology \& Public Policy, 11(2), 317-326.

Wickes, R., Zahnow, R., Schaefer, L, and Sparkes-Carroll, M. 2017. Neighborhood Guardianship and Property Crime Victimization. Crime \& Delinquency, 63(5), 519544.

Wilcox, P., Madensen, T.D, \& Tillyer, M.S. 2007. Guardianship in Context: Implications for Burglary Victimization Risk and Prevention. Criminology, 45(4), 771-803.

Wortley, R. 2012. Exploring the Person-Situation Interaction in Situational Crime Prevention. In: Tilley, N., and Farrell, G. (eds.) The Reasoning Criminologist: Essays in Honour of Ronald V. Clarke. London: Routledge. 
Table 1: Characteristics of interview participants $(N=20)$

\begin{tabular}{|c|c|c|c|c|c|c|}
\hline & $n$ & $\%$ & Min & Max & $\bar{x}$ & $S D$ \\
\hline \multicolumn{7}{|l|}{ Gender } \\
\hline Male & 8 & 40.0 & & & & \\
\hline Female & 12 & 60.0 & & & & \\
\hline \multicolumn{7}{|l|}{ Education } \\
\hline $10^{\text {th }}$ grade or below & 0 & 0.0 & & & & \\
\hline $12^{\text {th }}$ grade & 2 & 10.0 & & & & \\
\hline Diploma & 2 & 10.0 & & & & \\
\hline Undergraduate degree & 10 & 50.0 & & & & \\
\hline Postgraduate degree & 6 & 30.0 & & & & \\
\hline \multicolumn{7}{|l|}{ Relationship status } \\
\hline Single/Never married & 1 & 5.0 & & & & \\
\hline Married/de-facto & 17 & 85.0 & & & & \\
\hline Divorced & 2 & 10.0 & & & & \\
\hline Widowed & 0 & 0.0 & & & & \\
\hline \multicolumn{7}{|l|}{ Australian born } \\
\hline Yes & 19 & 95.0 & & & & \\
\hline No & 1 & 5.0 & & & & \\
\hline \multicolumn{7}{|l|}{ Employment } \\
\hline Unemployed & 1 & 5.0 & & & & \\
\hline Full time & 10 & 50.0 & & & & \\
\hline Part time/casual & 6 & 30.0 & & & & \\
\hline Not in labour force & 3 & 15.0 & & & & \\
\hline \multicolumn{7}{|l|}{ Living status } \\
\hline Live with partner & 7 & 35.0 & & & & \\
\hline Live with partner and children & 10 & 50.0 & & & & \\
\hline Live with children & 1 & 5.0 & & & & \\
\hline Live with other family & 0 & 0.0 & & & & \\
\hline Live with parents & 0 & 0.0 & & & & \\
\hline Live with friends & 0 & 0.0 & & & & \\
\hline Live alone & 2 & 10.0 & & & & \\
\hline Age (years) & & & 24 & 83 & 46.8 & 14.5 \\
\hline Length of residence (years) & & & 0.5 & 32 & 9.4 & 7.9 \\
\hline
\end{tabular}


Table 2: Type of response among suburban residents who reportedly witnessed crimes or suspicious events $(N=22)$

\begin{tabular}{lrr}
\hline & \multicolumn{2}{c}{$\begin{array}{c}\text { Witnessed a crime or } \\
\text { suspicious event }\end{array}$} \\
\hline Type of response & $n$ & $\%$ \\
\hline Direct intervention & 5 & 22.73 \\
Indirect intervention & 3 & 13.64 \\
Monitored situation & 12 & 54.55 \\
Did nothing & 2 & 9.09 \\
\hline Total & 22 & 100.00 \\
\hline
\end{tabular}

Note: Residents could have reportedly witnessed more than one crime or suspicious event. Detail may not add to $100 \%$ due to rounding. 
Table 3. Characteristics associated with four types of suburban residential guardians

\begin{tabular}{|c|c|c|c|c|}
\hline Typology & PAMS & POMS & $\overline{R E M}$ & NOM \\
\hline Characteristics & $\begin{array}{ll}\text { - } & \text { Prior } \\
\text { victimisation } \\
\text { - } & \text { Crime } \\
\text { prevention } \\
\text { - } & \text { Relationship } \\
\text { with } \\
\text { neighbours } \\
\text { - } \\
\text { Enjoyment } \\
\text { or leisure }\end{array}$ & $\begin{array}{ll}\text { - } & \text { Housing } \\
\text { design } & \\
\text { facilitated } \\
\text { natural } \\
\text { surveillance } \\
\text { - } & \text { Routine } \\
\text { activities at } \\
\text { home }\end{array}$ & $\begin{array}{ll}\text { - } & \text { Unusual or } \\
\text { unfamiliar } \\
\text { noise }\end{array}$ & 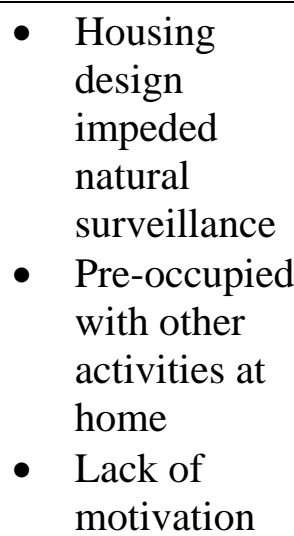 \\
\hline
\end{tabular}

Purposefully active monitors (PAMS); Passive opportunistic monitors (POMS); Responsive monitors (REM); and Non-monitors (NOM). 